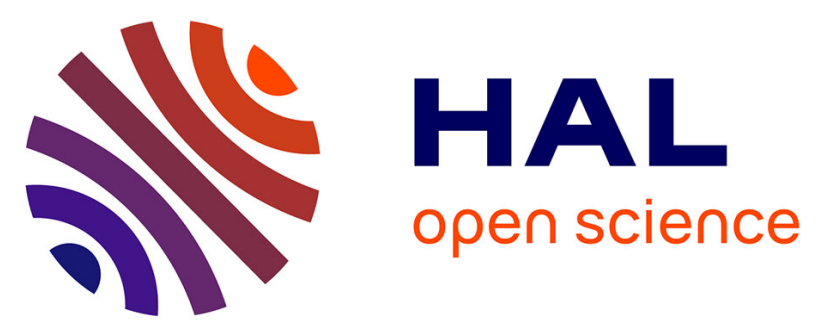

\title{
Ensuring Robust and Tissue-Independent Operation of Implantable, Ingestible, and Injectable Antennas
}

\author{
D. Nikolayev, W. Joseph, M. Zhadobov, Ronan Sauleau, L. Martens
}

\section{To cite this version:}

D. Nikolayev, W. Joseph, M. Zhadobov, Ronan Sauleau, L. Martens. Ensuring Robust and TissueIndependent Operation of Implantable, Ingestible, and Injectable Antennas. 13th International Symposium on Medical Information and Communication Technology, ISMICT 2019, May 2019, Oslo, Norway. pp.8743831, 10.1109/ISMICT.2019.8743831 . hal-02281669

\section{HAL Id: hal-02281669}

\section{https://hal-univ-rennes1.archives-ouvertes.fr/hal-02281669}

Submitted on 2 Nov 2020

HAL is a multi-disciplinary open access archive for the deposit and dissemination of scientific research documents, whether they are published or not. The documents may come from teaching and research institutions in France or abroad, or from public or private research centers.
L'archive ouverte pluridisciplinaire HAL, est destinée au dépôt et à la diffusion de documents scientifiques de niveau recherche, publiés ou non, émanant des établissements d'enseignement et de recherche français ou étrangers, des laboratoires publics ou privés. 


\section{Ensuring Robust and Tissue-Independent Operation of Implantable, Ingestible, and Injectable Antennas}

\author{
Denys Nikolayev \\ $M A G-S C I-S T I-A S$ \\ EPFL \\ Lausanne, Switzerland \\ $\mathrm{d} @$ deniq.com \\ Ronan Sauleau \\ IETR - UMR CNRS 6164 \\ Université de Rennes 1 \\ Rennes, France \\ Ronan.Sauleau@univ-rennes1.fr
}

\author{
Wout Joseph \\ INTEC - WAVES \\ imec / Ghent University \\ Ghent, Belgium \\ Wout.Joseph@UGent.be \\ Luc Martens \\ INTEC - WAVES \\ imec / Ghent University \\ Ghent, Belgium \\ Luc1.Martens@ugent.be
}

\author{
Maxim Zhadobov \\ IETR - UMR CNRS 6164 \\ Université de Rennes 1 \\ Rennes, France \\ Maxim.Zhadobov@univ-rennes1.fr
}

\begin{abstract}
In-body bioelectronics relies on antennas to interface with external on- or off-body equipment. In this paper, we address the impedance detuning of in-body antennas caused by nondeterministic electromagnetic properties of biological tissues. The impedance robustness can be improved in two ways. First, by using wideband and multiresonance antennas with an added benefit of higher achievable data rates. Second, by applying specific dielectric-loaded narrow-band microstrip designs that additionally show enhanced radiation performance and robustness to inner components. Fully tissue-independent characteristics can be realized using hybrid slot-patch designs.
\end{abstract}

Keywords-antenna, bioelectronics, implantable, in-body, ingestible, injectable, microstrip antenna, robustness

\section{INTRODUCTION}

Autonomous implantable, ingestible, and injectable (inbody) bioelectronics offer powerful capabilities in medicine, clinical research, occupational health, and professional sports [1]-[3]. Specifically, wireless biotelemetry allows for monitoring of a wide range of human or animal physiological parameters: vitals, blood tests, and so on. Precision medicine requires precision diagnostics [4], and miniature implants make it possible to yield more precise information than ever before about one's health (Fig. 1). Neural interfaces allow us to study the brain via mapping, assisting, augmenting, and repairing cognitive or sensory-motor functions [5]. The emerging concept of electroceuticals aims individual nerve fibers or specific neural circuits that regulate organs to treat an array of conditions [6].

In-body bioelectronics uses radiofrequency (RF) antennas to communicate with external on- or off-body systems. A wide range of RF antennas has been proposed for body-implantable applications [3]. So far, establishing a robust link between an

This publication is supported by the European Union through the European Regional Development Fund (ERDF), and by the French region of Brittany, Ministry of Higher Education and Research, Rennes Métropole and Conseil Départemental 35, through the CPER SOPHIE/STIC \& Ondes.

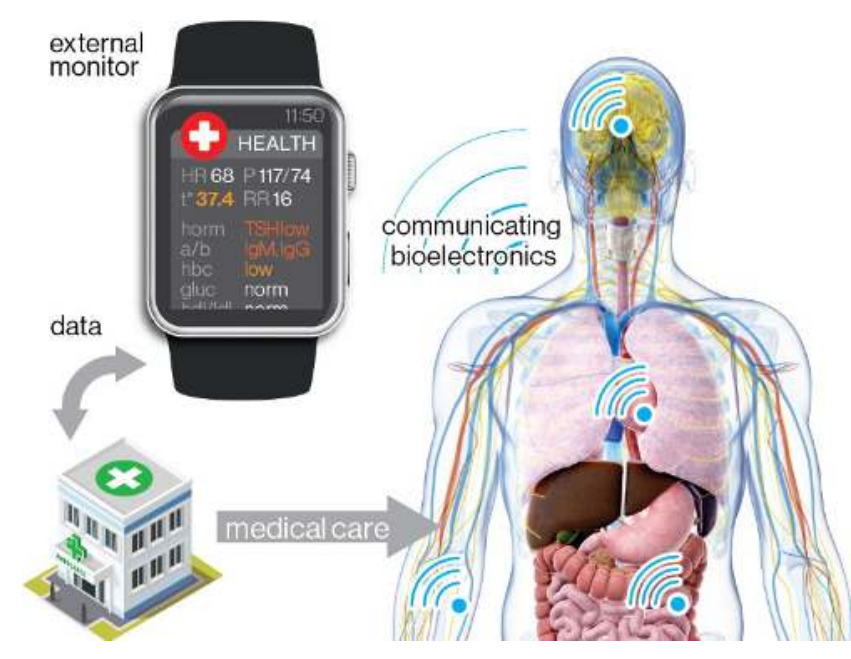

Fig. 1. Application example (biotelemetry) of implantable, ingestible, and injectable wireless bioelectronics.

in-body device and external equipment remains a major challenge because of to low total efficiencies $\left(\eta_{\text {tot }}<0.1 \%\right)$ of the antennas operating in lossy media with uncertain electromagnetic (EM) properties. In addition to improved communication link, efficient and robust in-body antennas allow for minimization of measurement errors in path loss characterization in vivo, especially for deep-body locations in large animals.

In this paper, we 1) review the design challenges and 2) provide guidelines on how to ensure the robust and tissueindependent operation of in-body antennas.

\section{Design Challenges}

The radiation performance of in-body antenna strongly depends on dispersive EM properties of surrounding tissues [7] (characterized by the complex permittivity $\hat{\varepsilon}(\omega)=\varepsilon^{\prime}-j \varepsilon^{\prime \prime}$, where $\omega=2 \pi f$ is the angular frequency). The evanescent fields dissipate and the radiated power attenuates due to tissue losses 
$\varepsilon^{\prime \prime}=\sigma / \omega$ (where $\sigma$ is the conductivity). The attenuation $\alpha$ is proportional to frequency $f$.

The propagating wave scatters because of the significant tissue heterogeneity $\varepsilon(\mathbf{r})$ and high wave-impedance contrast $\Delta Z$ between the tissues and free space; $\Delta Z \propto 1 / f[8]$. Therefore, for a given electrical size $k a$ of the antenna, the achievable radiation efficiency $\eta$ can be improved by choosing an optimal operating frequency $f_{\text {opt. }}$. The optimal frequency is a tradeoff between $\alpha$ on the one hand and $\Delta Z$ on the other [9].

Caused by heterogeneous and nondeterministic nature of tissue effective-EM properties [8], the antenna impedance detuning strongly affects the total efficiency of the antenna $\eta_{\text {tot }}=$ $\eta\left(1-|\Gamma|^{2}\right)$, where $\Gamma$ is the reflection coefficient. The conductivity $\sigma$ of surrounding tissues affects the bandwidth and $\eta$ [10]. The relative permittivity $\varepsilon_{r}$ loads the antenna reducing its resonant frequency. Note that this dielectric loading also increases the electrical size $k a$ of the antenna improving $\eta$ [11]

The wider is the range of EM properties the antenna can handle (i.e. matching remains below $\left|S_{11}\right| \leq-10 \mathrm{~dB}$ ), the more it is considered robust. Tissue-independent antenna, therefore, can operate in all body tissues [12]. Such antenna allows for its application in a wide range of scenarios. For instance, the same device can be used as an ingestible for humans and as an implantable for animals that can range in size from a mouse to a cow [13].

An in-body device typically contains various electronic and biomedical circuits, sensors, and a power source. These inner components can affect the antenna impedance performance as well and must be taken into account during the numerical analysis of the antenna.

\section{ENSURING ROBUST OPERATION}

To analyze the impedance robustness of the antenna to tissues, we use an isotropic homogeneous $\varnothing 100$-mm spherical phantom (Fig. 2) [14]. The EM properties $\left(\varepsilon_{r}, \sigma\right)$ are parametrized to span the whole range of tissue EM properties: from fat (the lowest) to cerebrospinal fluid (the highest) [8].

\section{A. Design Approaches}

1) Wideband antennas - The most common approach to improving detuning immunity of in-body antennas is to yield a sufficiently large bandwidth. Ultra-wideband designs have been proposed recently [15]-[17]. In addition to improved robustness, such antennas allow for higher achievable data rates. The ultra-wideband designs typically ensure operation in muscle and gastrointestinal tract (GI) tissues.

Going beyond this range of EM properties requires further increasing the bandwidth. For a given $k a$, this usually involves increasing antenna losses by, for instance, reinforcing the coupling with surrounding tissues. Obviously, this leads to deterioration of the radiation efficiency. With rare exceptions, wideband in-body antennas are based on loop designs that could be sensitive to the inner components of the device due to the absence of the ground plane.

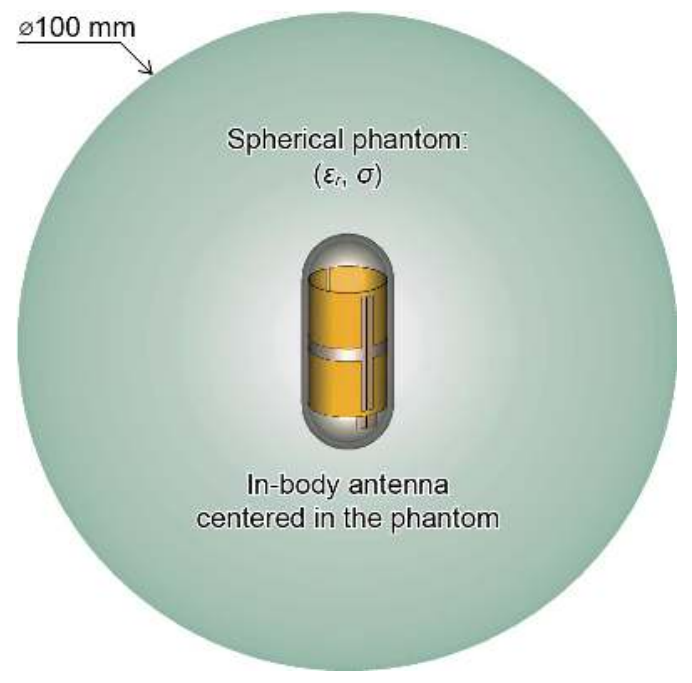

Fig. 2. Evaluation of impedance robustness to tissues (phantom not to scale). The antenna is centered in a $\varnothing 100-\mathrm{mm}$ spherical phantom with varying EM properties.

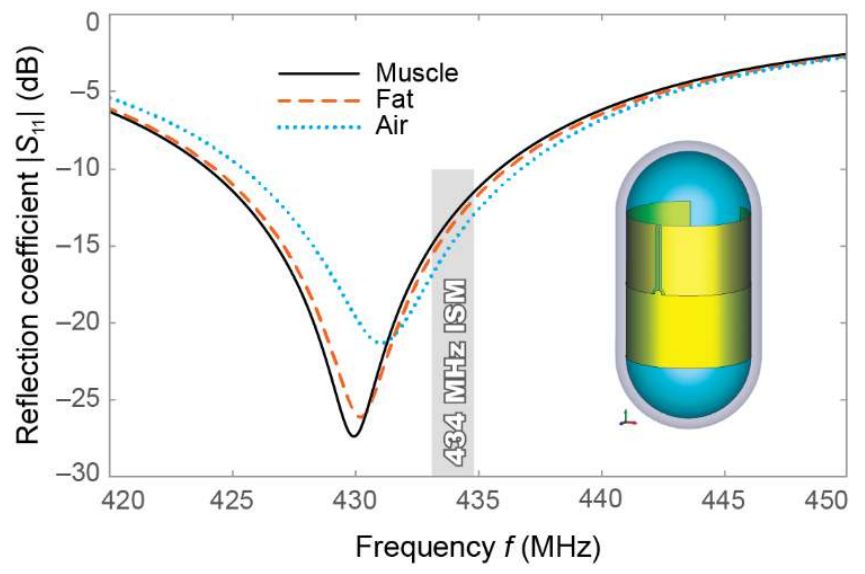

Fig. 3. Reflection coefficient $\left|S_{11}\right|$ of the slot-patch antenna computed in air and in a $\varnothing 100$-mm spherical phantom (Fig. 2) with mucle- and fatequivalent EM properties.

2) Multiresonance antennas - An alternative to wideband approach would be to design an antenna with multiple resonances covering the EM properties of the tissues surrounding the antenna ranging from high to low water content. This multiresonance method was implemented in [12]. The antenna is based on folded-meandered dipole design and shows good matching $\left(\left|S_{11}\right|<-10 \mathrm{~dB}\right)$ in all high-water-contents tissues (note that these include all gastrointestinal tract tissues). The matching in fat is $\left|S_{11}\right| \approx-8 \mathrm{~dB}$.

3) Dielectric-loaded microstrip antennas-Having relatively narrow bandwidths, specific dielectric-loaded microstrip designs allow reducing the effect of uncertain EM properties on the antenna impedance. Representing a microstrip antenna as a combination of transmission line sections [18], one can see that the resonance frequency of the antenna depends on the characteristic impedance $Z_{0}$ of each microstrip section. This characteristic impedance is defined mostly by the 
invariable geometry and EM properties of the substrate and superstrate [19]. The E-field fringing into the tissues with variable EM properties accounts for the antenna detuning. These fringing fields can be partially withdrawn from the tissues by using high-permittivity superstrates of sufficient thickness.

In addition to the enhanced robustness, this approach does not require sacrificing the radiation efficiency of the antenna. On the contrary, it allows improving the theoretically achievable efficiency by increasing the electrical size of the antenna. This approach was demonstrated in [18] using a miniature 434-MHz microstrip antenna (Fig. 2) loaded with a 0.5 -mm-thick alumina superstrate $\left(\varepsilon_{r} \approx 10\right)$. The antenna shows good matching in all high-water-content tissues $\left(\left|S_{11}\right|<\right.$ $-10 \mathrm{~dB}$ ) having a radiation efficiency of $0.4 \%$ and gain $G=-$ $22 \mathrm{dBi}$ (in a $\varnothing 100$-mm muscle-equivalent phantom, Fig. 2).

4) Hybrid slot-patch antennas-Dielectric loading of microstrip antennas requires costly materials that limit the scope of potential applications. Using low-cost materials (usually, lower-permittivity biocompatible plastics) results in stronger antenna coupling to the surrounding lossy tissues and, therefore, reduced robustness. Sections of microstrip antennas with high characteristic impedance (high- $Z_{0}$ ) are the most affected because of larger fringing fields penetrating into the tissues.

Realizing the high- $Z_{0}$ sections as coplanar-slot lines in the ground plane moves the fringing fields inside of the low-loss device and away from the tissues. This helps to reduce the variance of effective EM properties in the near-field zone of the antenna hence results in significantly improved robustness at a cost of the radiation performance. Fig. 3 shows the impedance performance of a novel hybrid slot-patch antenna [13].

The proposed design remains well matched in both air and body tissues, which is, to the best of our knowledge, the first of its kind. However, the radiation performance of the antenna $(G=-34 \mathrm{dBi})$ stays comparable with counterparts [9], but it is less efficient than the dielectric-loaded antennas using materials with $\varepsilon_{r} \geq 10$.

\section{CONCLUSION}

We reviewed the design challenges and approaches to tissue-independent wireless operation of implantable bioelectronics. Robust antenna characteristics can be achieved using 1) wideband and multiresonance antennas with an added benefit of improved data rates or 2) dielectric-loaded narrowband microstrip designs showing better radiation performance and robustness to inner components.

Fully tissue-independent characteristics can be realized using hybrid slot-patch designs. Such antennas are promising candidates for subject-independent applications. For instance, it can be used as an ingestible for humans or as an implantable for a wide range of animals: from rodents to cattle.

Moreover, robust and efficient in-body antennas allow for minimization of measurement errors in path loss characterization in vivo, especially for deep-body applications or in large animals [20].
The considered antenna designs (both in planar and conformal realizations) can also find their applications in other non-medical fields where establishing robust communication links is required with devices in highpermittivity and lossy environments.

\section{REFERENCES}

[1] A. S. Y. Poon, "Miniaturized Biomedical Implantable Devices," in Implantable Bioelectronics, Weinheim, Germany: Wiley-VCH, 2014, pp. 45-64.

[2] A. Kiourti and K. S. Nikita, "A review of in-body biotelemetry devices: implantables, ingestibles, and injectables," IEEE Trans. Biomed. Eng., vol. 64, no. 7, pp. 1422-1430, Jul. 2017.

[3] D. Nikolayev, M. Zhadobov, R. Sauleau, and P. Karban, "Antennas for ingestible capsule telemetry," in Advances in Body-Centric Wireless Communication: Applications and State-of-the-Art, London, UK: IET, 2016, pp. 143-186.

[4] S. J. Aronson and H. L. Rehm, "Building the foundation for genomics in precision medicine," Nature, vol. 526, no. 7573, pp. 336-342, Oct. 2015.

[5] J. J. Jun et al., "Fully integrated silicon probes for high-density recording of neural activity," Nature, vol. 551, no. 7679, pp. 232-236, Nov. 2017.

[6] K. Famm, B. Litt, K. J. Tracey, E. S. Boyden, and M. Slaoui, "Drug discovery: A jump-start for electroceuticals," Nature, vol. 496, pp. 159-161, Apr. 2013.

[7] D. Nikolayev, M. Zhadobov, P. Karban, and R. Sauleau, "Electromagnetic radiation efficiency of body-implanted devices," Phys. Rev. Applied, vol. 9, no. 2, p. 024033, Feb. 2018.

[8] S. Gabriel, R. W. Lau, and C. Gabriel, "The dielectric properties of biological tissues: II. Measurements in the frequency range $10 \mathrm{~Hz}$ to 20 GHz," Phys. Med. Biol., vol. 41, pp. 2251-2269, Nov. 1996.

[9] D. Nikolayev, M. Zhadobov, P. Karban, and R. Sauleau, "Conformal antennas for miniature in-body devices: The quest to improve radiation performance," URSI Rad. Sci. Bull., vol. 2017, no. 363, pp. 52-64, Dec. 2017.

[10] A. Karlsson, "Physical limitations of antennas in a lossy medium," IEEE Trans. Antennas Propag., vol. 52, no. 8, pp. 2027-2033, Aug. 2004.

[11] D. Nikolayev, M. Zhadobov, and R. Sauleau, "Impact of tissue electromagnetic properties on radiation performance of in-body antennas," IEEE Antenn. Wireless Propag. Lett., vol. 17, no. 8, pp. 1440-1444, Aug. 2018.

[12] M. K. Magill, G. A. Conway, and W. G. Scanlon, "Tissue-independent implantable antenna for in-body communications at $2.36-2.5 \mathrm{GHz}$," IEEE Trans. Antennas Propag., vol. 65, no. 9, pp. 4406-4417, Sep. 2017.

[13] D. Nikolayev, M. Zhadobov, and R. Sauleau, "Immune-to-detuning wireless in-body platform for versatile biotelemetry applications," IEEE Trans. Biomed. Circuits Syst., vol. 13, no. 2, pp. 403-412, Apr. 2019.

[14] D. Nikolayev, W. Joseph, M. Zhadobov, R. Sauleau, and L. Martens, "Optimal radiation of body-implanted capsules," Phys. Rev. Lett., vol. 122, no. 10, p. 108101, Mar. 2019.

[15] Z. Bao, Y. X. Guo, and R. Mittra, "An ultrawideband conformal capsule antenna with stable impedance matching," IEEE Trans. Antennas Propag., vol. 65, no. 10, pp. 5086-5094, Oct. 2017.

[16] M. S. Miah, A. N. Khan, C. Icheln, K. Haneda, and K. Takizawa, "Antenna system design for improved wireless capsule endoscope links at 433 MHz," IEEE Trans. Antennas Propag., vol. 67, no. 4, pp. 26872699, Apr. 2019.

[17] R. S. Alrawashdeh, Y. Huang, M. Kod, and A. A. B. Sajak, "A broadband flexible implantable loop antenna with complementary split ring resonators," IEEE Antenn. Wireless Propag. Lett., vol. 14, pp. 1506-1509, Feb. 2015.

[18] D. Nikolayev, M. Zhadobov, L. Le Coq, P. Karban, and R. Sauleau, "Robust ultra-miniature capsule antenna for ingestible and implantable applications," IEEE Trans. Antennas Propag., vol. 65, no. 11, pp. 6107-6119, Nov. 2017.

[19] D. M. Pozar, Microwave engineering, $4^{\text {th }}$ ed. Hoboken, NJ: Wiley, 2012.

[20] S. Benaissa et al., "Experimental characterization of in-to-out-body path loss at $433 \mathrm{MHz}$ in dairy cows," Electron. Lett., vol. 55, no. 7, pp. 422-424, Apr. 2019. 